\title{
Three-dimensional limit equilibrium analysis of open pits
}

\author{
H.H. Lu SoilVision Systems Ltd., Canada \\ M.D. Fredlund SoilVision Systems Ltd., Canada \\ D.G. Fredlund Golder Associates Ltd., Canada
}

\begin{abstract}
The analysis of slope stability in the design and ongoing operations of any particular open pit remains a difficult challenge. Slope failures and loss of equipment, mining time, and lives make stability concerns an issue which warrants research efforts. Engineers have relied for decades on software tools to perform analysis of the slopes of open pits in order to estimate the Factor of Safety (FS). Usually open pit geometry is typical three-dimensional (3D) geometry which cannot adequately be simplified into a two-dimensional (2D) plane strain representation. Traditional analysis has been performed using $2 D$ limit equilibrium methods (LEM) since this method continues to be the simplest to apply. This paper examines the application of the 3D LEM to analyse the slopes of an open pit. The 3D LEM has advantages in that it can consider slips at any particular azimuth vector angle (i.e. it can search the whole 3D open pit model and find the critical slip surface, and critical slip vector). The results of $3 D$ LEM are compared with results from $2 D$ LEM analysis. The result is a methodology which is credible and applicable within a reasonable time frame for the analysis of open pits.
\end{abstract}

\section{Introduction}

Two-dimensional (2D) limit equilibrium methods (LEM) are the most common methodology used to analyse the stability of slopes. For any 2D LEM analysis, it is assumed that 1) the slope surface is infinite in the transverse direction, (i.e. plane strain conditions); and 2) the sliding direction is predefined, (i.e. the sliding direction is parallel to the $2 \mathrm{D}$ cross section model cutting direction of the slope). Usually open pit geometries are typically 3D in character and cannot be simplified onto a 2D plane strain model. In addition, the sliding direction cannot be predefined. Studies have shown that 2D calculated Factors of Safety (FS) are always lower than 3D calculated FS (Cavounidis, 1987). Consequently, it has become common to assume that the 2D FS always corresponds to the most pessimistic slip surface section that can be analysed. For complex geometries, many 2D section models need to be analysed in order to find the least stable 2D cross section intersecting the 3D sliding area. Engineers would like to know how conservative the 2D FS is compared to the more rigorous 3D FS. In other words, what is the 'true' FS or the more realistic 3D FS. At stake are questions related to the possible increase of open pit depth and the design of the open pit side-slopes. Small changes in the overall pit slope angle of an open pit can have a significant effect on the amount of waste rock that needs to be moved and the overall economy of the open pit mining operation.

3D LEM slope stability analyses are still not routinely performed for open pit slope design. However, advances in 3D LEM analysis theory, the power of personal computers and the development of 3D LEM software packages have enabled engineers to performance 3D LEM analyses in practice. The slicing method in 2D LEM analyses has been extended into 3D LEM analysis with columns by various authors (Hovland, 1977; Zhang, 1988; Hungr et al., 1989; Lam and Fredlund, 1993; Cheng and, Yip 2007). Kalatehjari and Ali (2013) did an extensive review of 3D analyses. Studies have revealed that there are some advantages of 3D LEM over 2D LEM: 1) actual representation of the field geometry conditions. This can be referred to as 3D effects; and 2) Direction of sliding can become part of the solution. Open pits usually have a sliding direction that is difficult to be predefined because of the complex geometry layout. Yamagami and Jiang (1997), Cheng and Yip (2007) proposed methods to determine the sliding direction as part of the solution. 
In open pit mining, back-analysis of previous failures is often performed in practice in order to determine the strength of the rock mass (Sjoberg 1996, 1999). Large scale shear strength testing is usually not economically or practically feasible. The back-calculated shear strength parameters are often used to calculate the FS of an existing slope. For large scale rock masses, the back-analysis of previous failures is often seen as the only practical means of obtaining relevant material shear strength parameters. The 3D effects cannot be considered in a 2D model. In order for the back-calculated mobilised shear strength to reflect the 3D end effects, 3D LEM back-analysis should be used rather than a 2D analysis. If a 2D back-analysis is used, the strength parameters will be estimated as higher than actual and on the unsafe side. If such 2D back-analysed parameters are subsequently used on a 3D forward analysis the resulting FS may be higher than the actual value.

SoilVision Systems Ltd (SVS) have recently extended the popular 2D LEM slicing methods into 3D LEM column methods in its SVSLOPE 3D software package. The analyses include Bishop simplified method, Janbu simplified method, Spencer method, Morgenstern-Price method, GLE method, Sarma method, Lowe-Karafiath method, Corps of Engineers \#1 and \#2 methods. It is also possible to calculate the 3D FS with different sliding directions. Furthermore, the considerations of pore-water pressures, external loads, structural discontinuities, tension cracks and various kinds of reinforcements in its 3D package render the software package a suitable tool for the calculation of open pit slope stability.

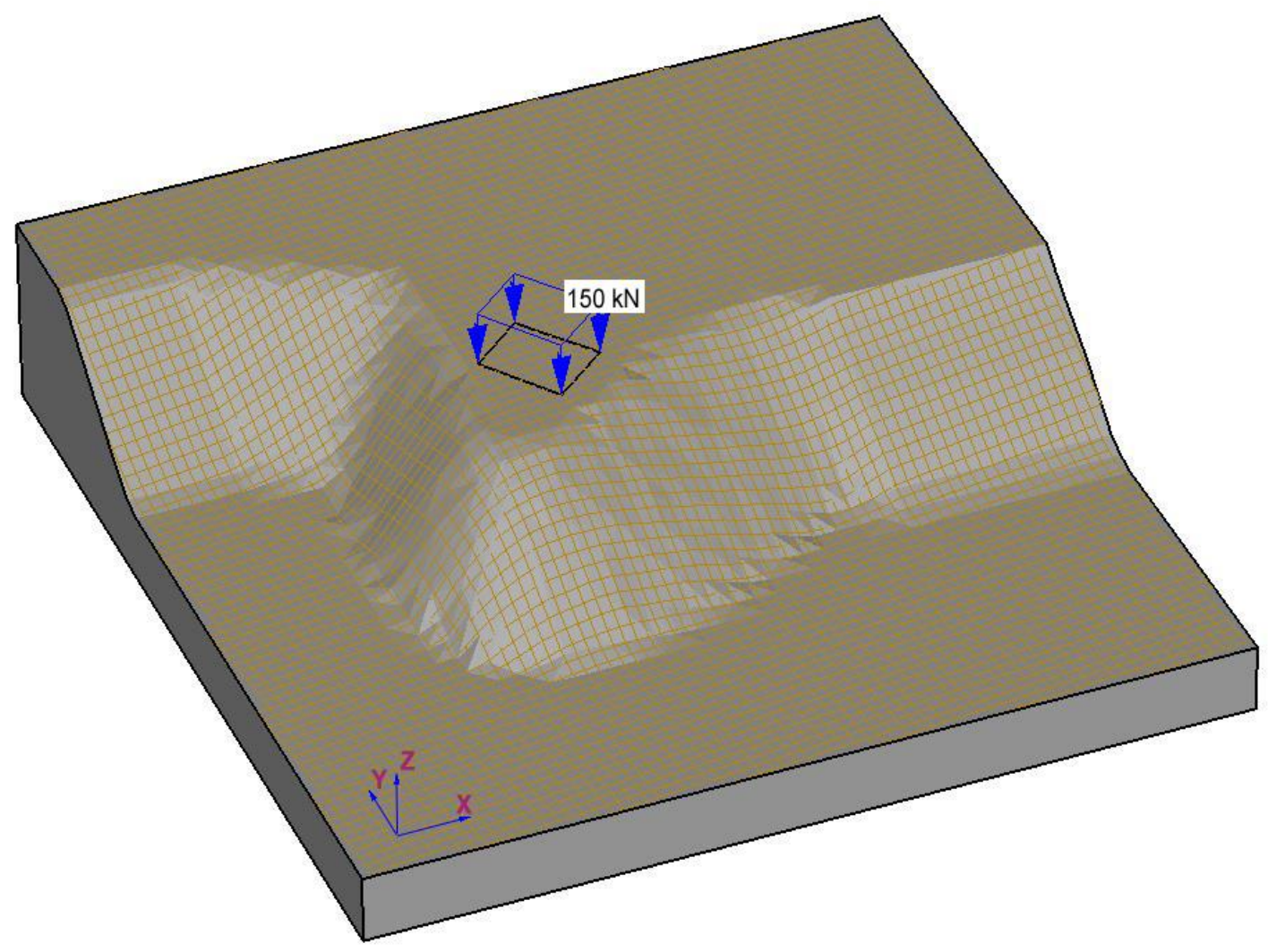

\section{Figure $13 \mathrm{D}$ view of a general slope model}

Open pit slope design requires information regarding the geological model, the structural model, the rock mass strength parameters and the hydrogeological conditions (Read and Stacey, 2009). A geotechnical slope stability model can be built with the specified information. Usually the geotechnical model is 3D in character and the sliding direction cannot be predefined for a particular slip surface. The location of the critical failure surface and its direction of movement proves to be a difficult global optimisation problem. Jiang (1997), Yamagami and Jiang (1997) provided a procedure that made use of the Janbu Simplified LEM method along with Dynamic Programming (DP) by Baker (1980) used a random number generation 
technique to find the critical slip surface and then used an optimisation procedure to find the critical slip surface direction. Cheng and Yip (2007) provided a formula to solve the 3D asymmetrical problem as an extension of the Morgenstern-Price's method and some other 2D limit equilibrium equations. Overall force and moment equilibrium equations were developed to calculate the FS in the $\mathrm{x}$ - and $\mathrm{y}$ - directions. With an assumed initial sliding direction of movement and several iterations, a unique value for the FS was obtained along with a unique direction of sliding. Cheng and Yip (2007) demonstrated that their formulation was actually equivalent to the axes rotation procedure by Yamagami and Jiang (1997) for finding the critical sliding direction.

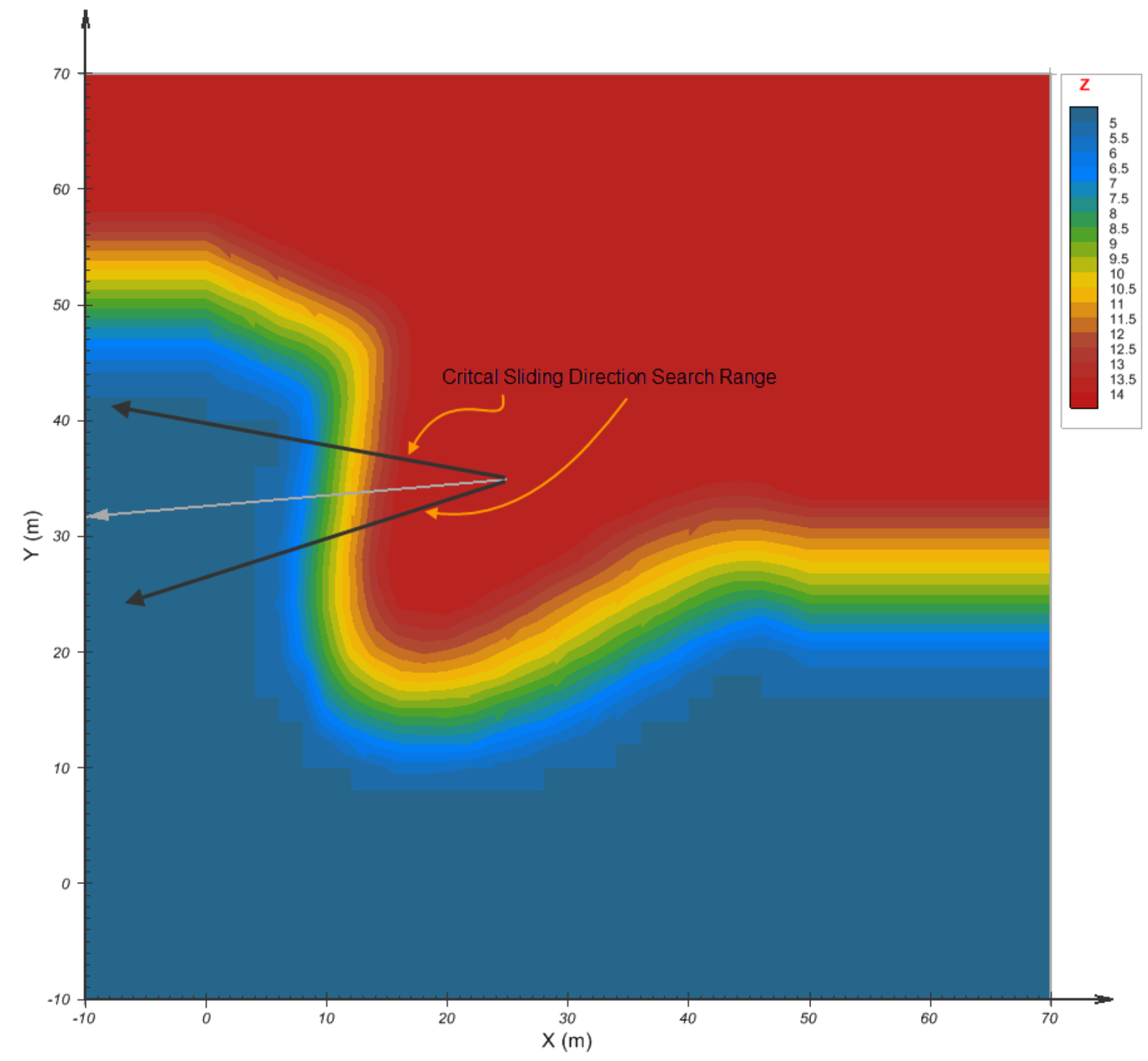

Figure 2 2D plan view of the general slope model

The Yamagami and Jiang (1997) sliding direction angle optimisation is based on the rotation of the axes. A similar concept is implemented in the SVSLOPE 3D by SoilVision Systems Ltd (SVS). Figure 1 shows a general 3D slope model. Figure 2 shows the contour of surface elevation in 2D view. The user first needs to specify the slope direction as shown in Figure 2 (i.e. the grey arrow line). Next, the user needs to specify the range of sliding directions as shown in the Figure 2 (with the dark arrow lines). The slope direction and search range can be specified based on the curvature of slope and change of elevation on a 2D plan contour plot. In order to find the critical sliding direction, the search range should be sub-divided into a number of 
smaller subregions. Gold Section Search (GSS) is used to optimise the search of rotation angle. According to Wikipedia, "The Golden Section Search is a technique for finding the extremum (minimum or maximum) of a strictly unimodal function by successively narrowing the range of values inside which the extremum is known to exist." The overall 3D model geometry including pore-water surface, reinforcement geometry and external loads are rotated to the direction vertical to $y$-axis and parallel to the XZ plane. Then the 3D LEM analysis is performed for a specific angle of rotation. There is a FS corresponding to each rotation angle. Iterations and optimisation are used to find the critical rotation angle with lowest FS.

\section{$3 \quad$ Example of a $3 \mathrm{D}$ open pit slope}

A typical open pit is used to demonstrate the application of 3D FEM analysis and rotation of sliding angles for finding the critical slip direction and the critical slip surface in an open pit mine. This open pit has been in production since 1906 and the open pit is almost $1 \mathrm{~km}$ deep and $4 \mathrm{~km}$ wide. The surface elevation data as shown in Figure 3 is based on a Digital Surface Model (DSM), which was provided by Intermap Technologies Corp., Calgary, Canada. No other geotechnical information was available for this open pit. The model shown in Figure 3 is only for demonstration purposes. Figure 4 shows the contours of the elevation of the open pit mine site surface.

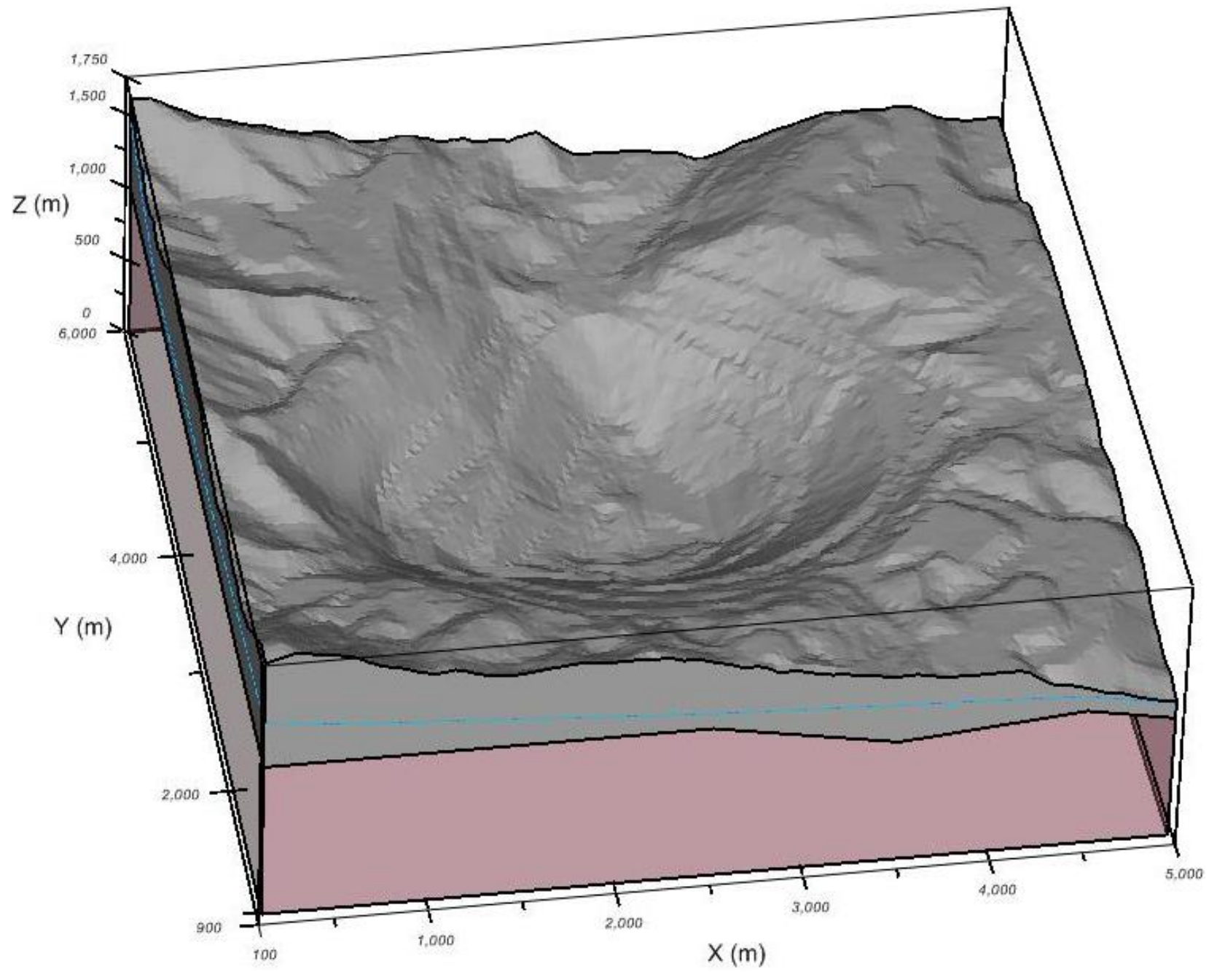

Figure 3 Conceptual $3 \mathrm{D}$ open pit model of the open pit 


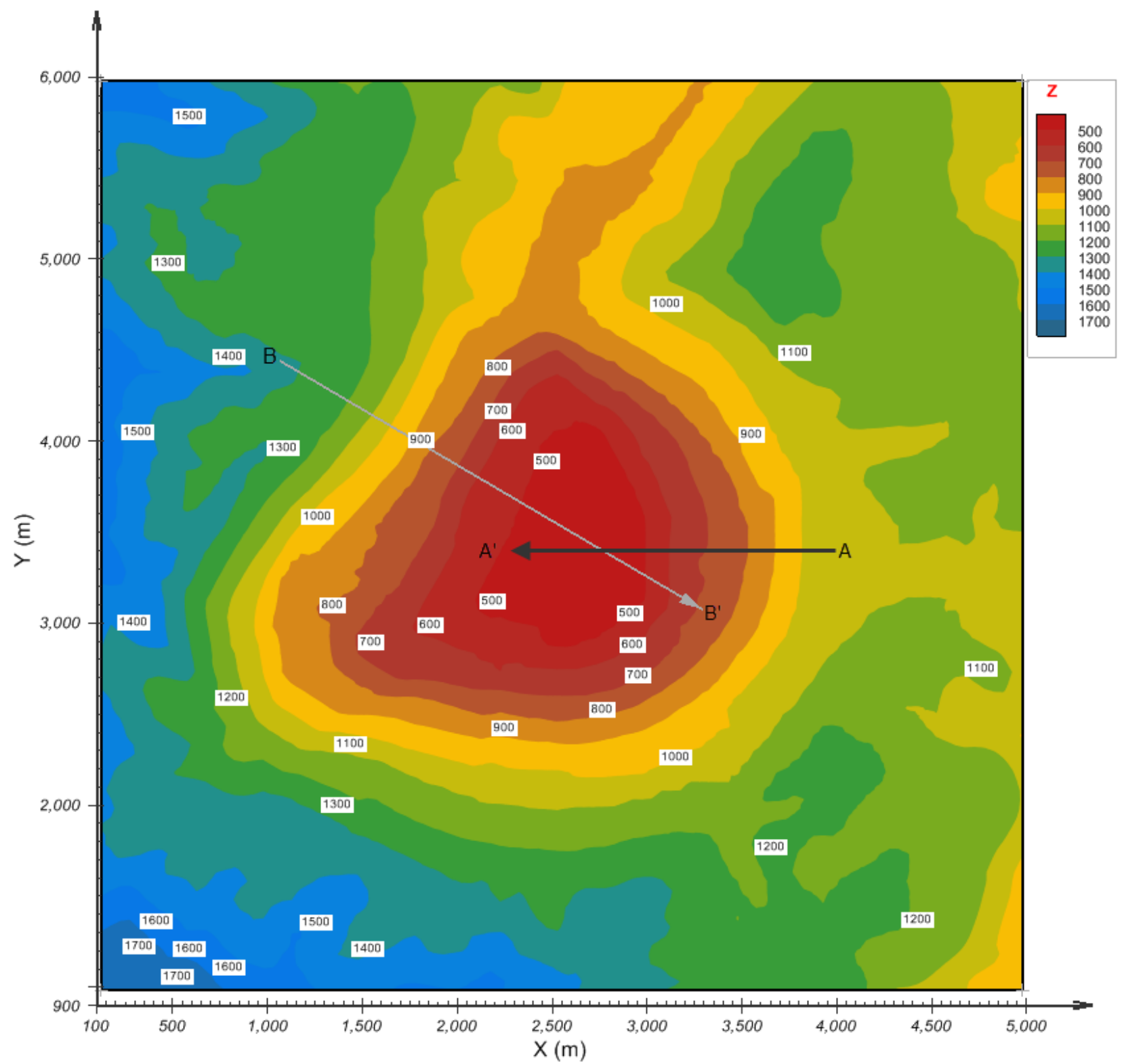

Figure 4 Contour of the elevation of the conceptual open pit

Let us assume that there are two different layers of rock mass in this model. The top layer of rock has cohesion equal to $100 \mathrm{kPa}$, angle of internal friction of $37^{\circ}$, and a unit weight of $29 \mathrm{kN} / \mathrm{m}^{3}$. The bottom hard rock layer has a cohesion equal to $500 \mathrm{kPa}$, an angle of internal friction of $39^{\circ}$ and a unit weight of $35 \mathrm{kN} / \mathrm{m}^{3}$. There is also pore-water pressure present in this model as shown in Figure 3 with blue lines and some of the following $2 \mathrm{D}$ section models.

\subsection{Case 1: slope direction A-A' (east slope sector)}

For the first case, let us consider the slope direction A-A' as shown in Figure 4. A 3D global LEM slope stability is analysed without giving consideration to the angle of rotation and a 2D LEM slope stability analysis is also performed. The results based on the Spencer method are shown in Table 1 . The sliding mass is shown in Figure 5 and Figure 6 for 3D and 2D, respectively. For this slope direction and geometry layout, the $3 \mathrm{D} F \mathrm{FS}$ is about $8 \%$ higher than the 2D FS. 
Table 1 Results of ${ }_{3} D$ and 2D LEM analysis based on Spencer method for case 1

\begin{tabular}{cc}
\hline 3D FS & 2D FS \\
\hline 1.583 & 1.46 \\
\hline
\end{tabular}

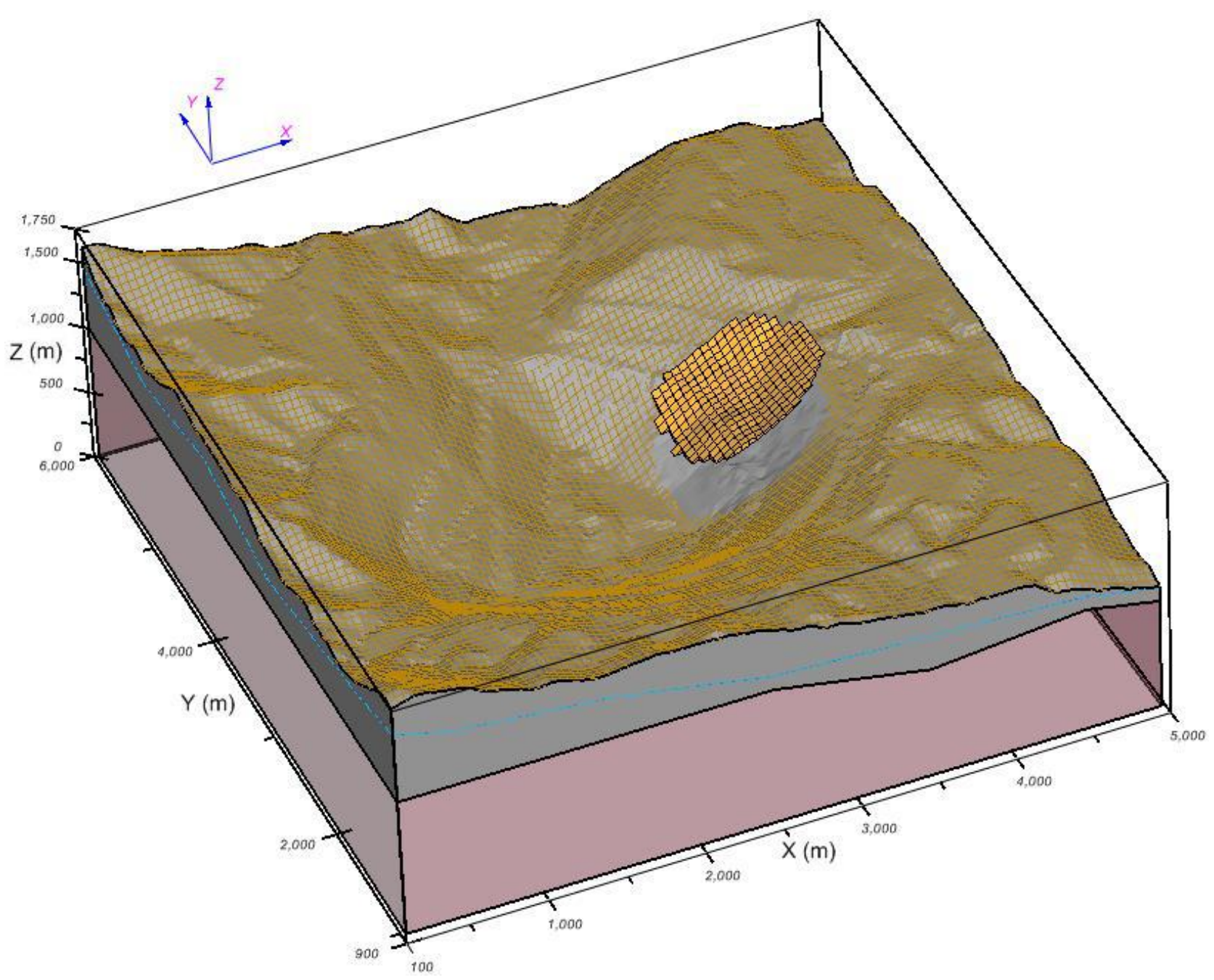

Figure $53^{\text {D }}$ critical slip surface of the east wall (slope direction A-A') 


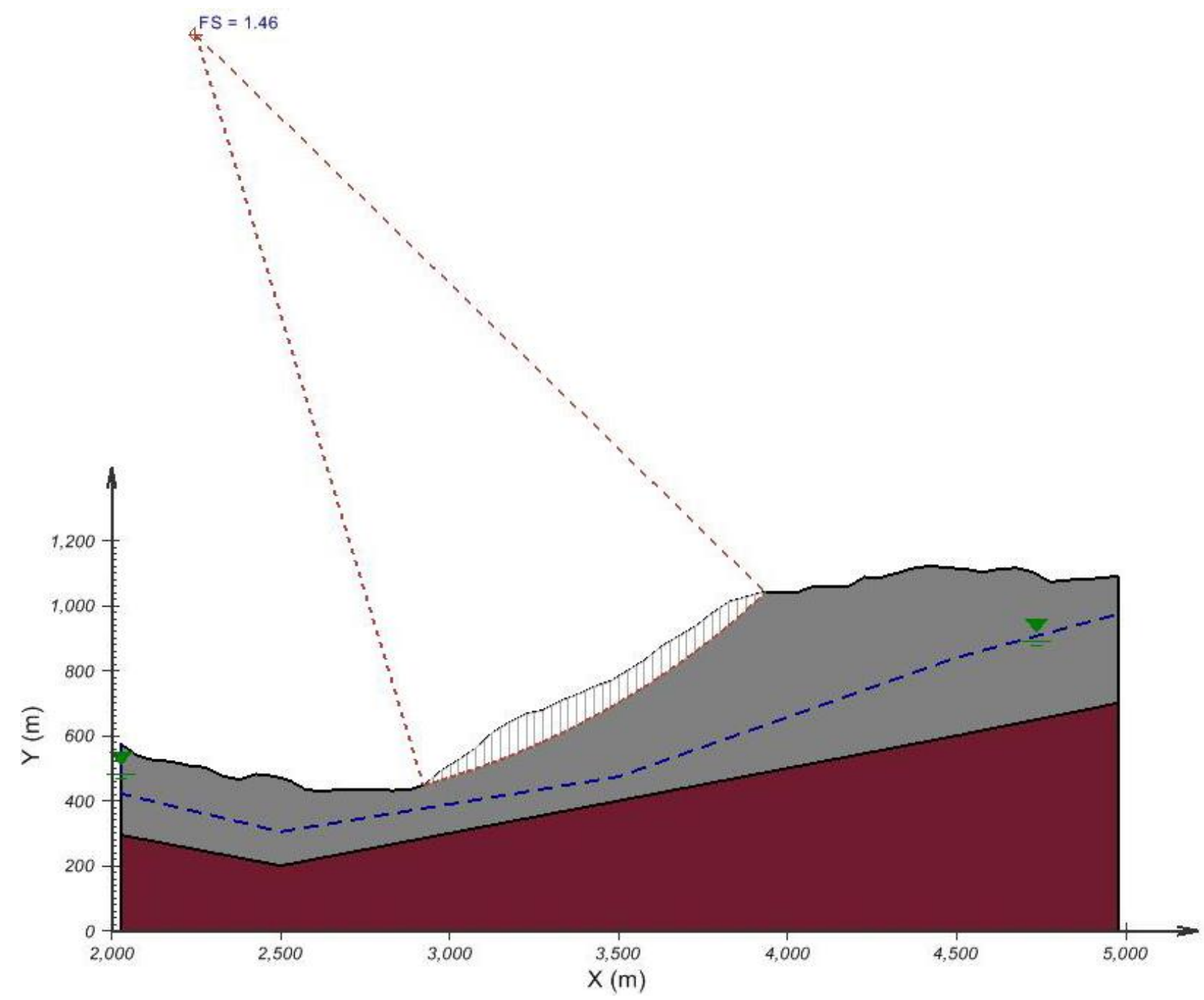

Figure 6 2D model and result based on cutting along slope direction A-A'

\subsection{Case 2: slope direction B-B' with axes rotation (northwest wall)}

For the second case, the slope direction B-B' as shown in Figure 4 is considered. A 3D slope stability analysis with axes rotation is performed in order to find the critical slip surface and its sliding direction. Figure 7 shows the 3D critical slip surface and Figure 8 shows the rotation angle versus FS. The sliding direction is $31.4^{\circ}$ (i.e. clockwise from positive $x$-axis direction) for this slope direction. A 2D section is cut along the 3D critical sliding direction to create a 2D model. Figure 9 shows the 2D model and its corresponding critical sliding surface. The FS result based on Bishop simplified method is shown in Table 2. For this slope direction and geometry layout, the 3D FS is about 7\% higher than 2D FS.

Table 2 Results of 3D and 2D LEM analysis based on Bishop simplified method for case 2

\begin{tabular}{cc}
\hline 3D (FS) & 2D (FS) \\
\hline 1.237 & 1.155 \\
\hline
\end{tabular}




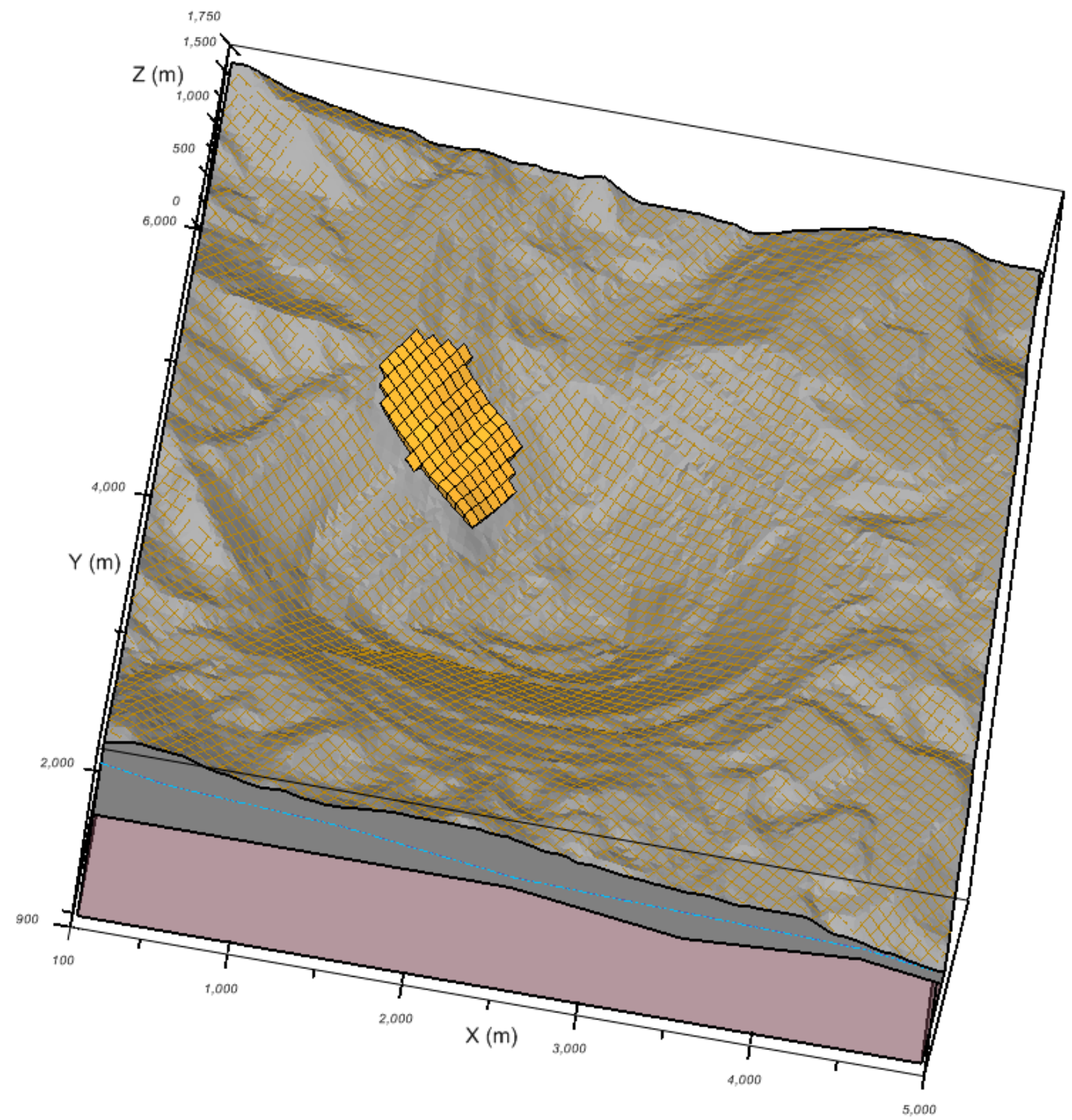

Figure $73^{D}$ critical slip surface of slope direction B-B' (northwest wall) 


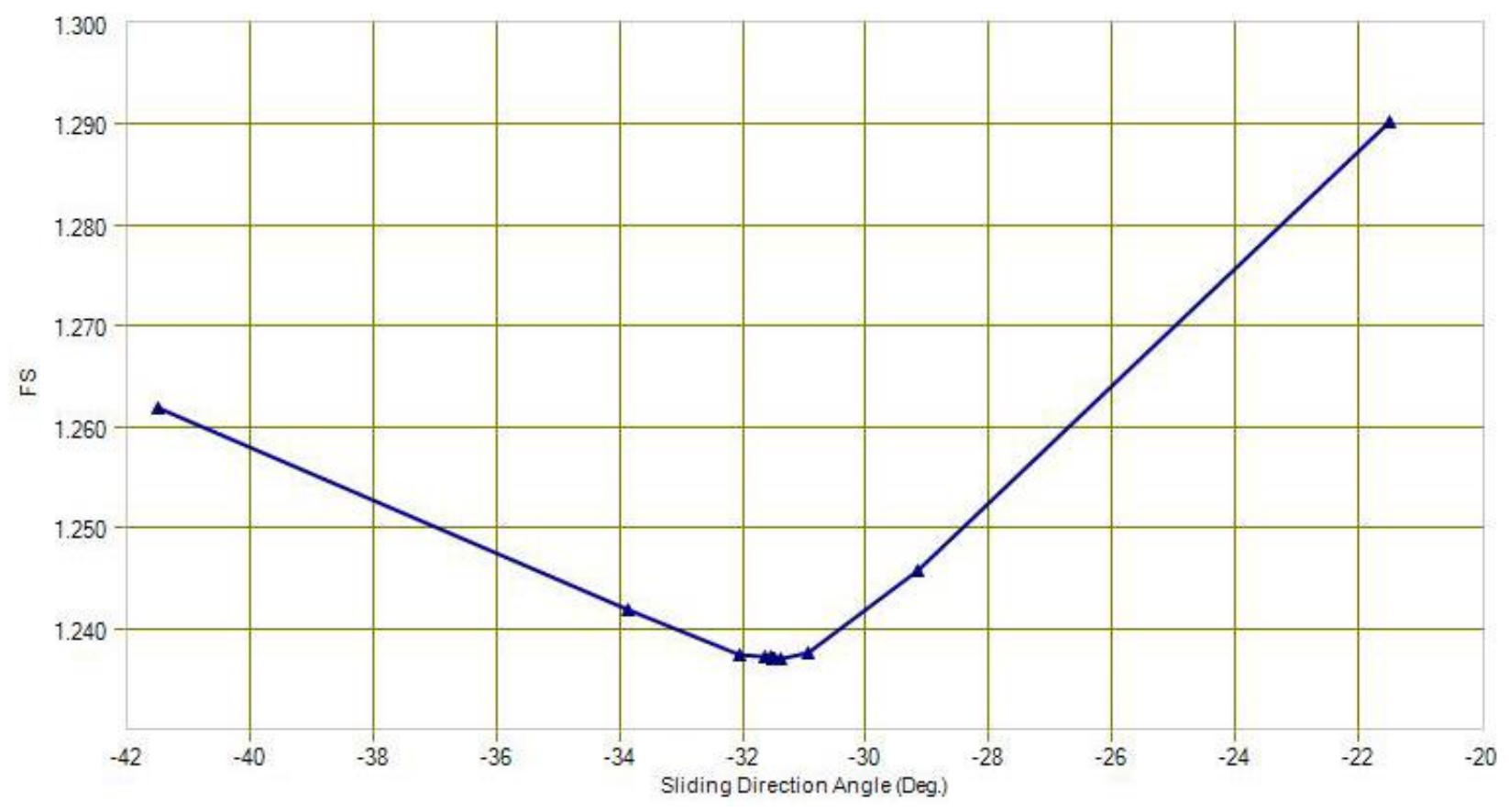

Figure 8 Sliding direction angle versus 3D FS for slope direction B-B'

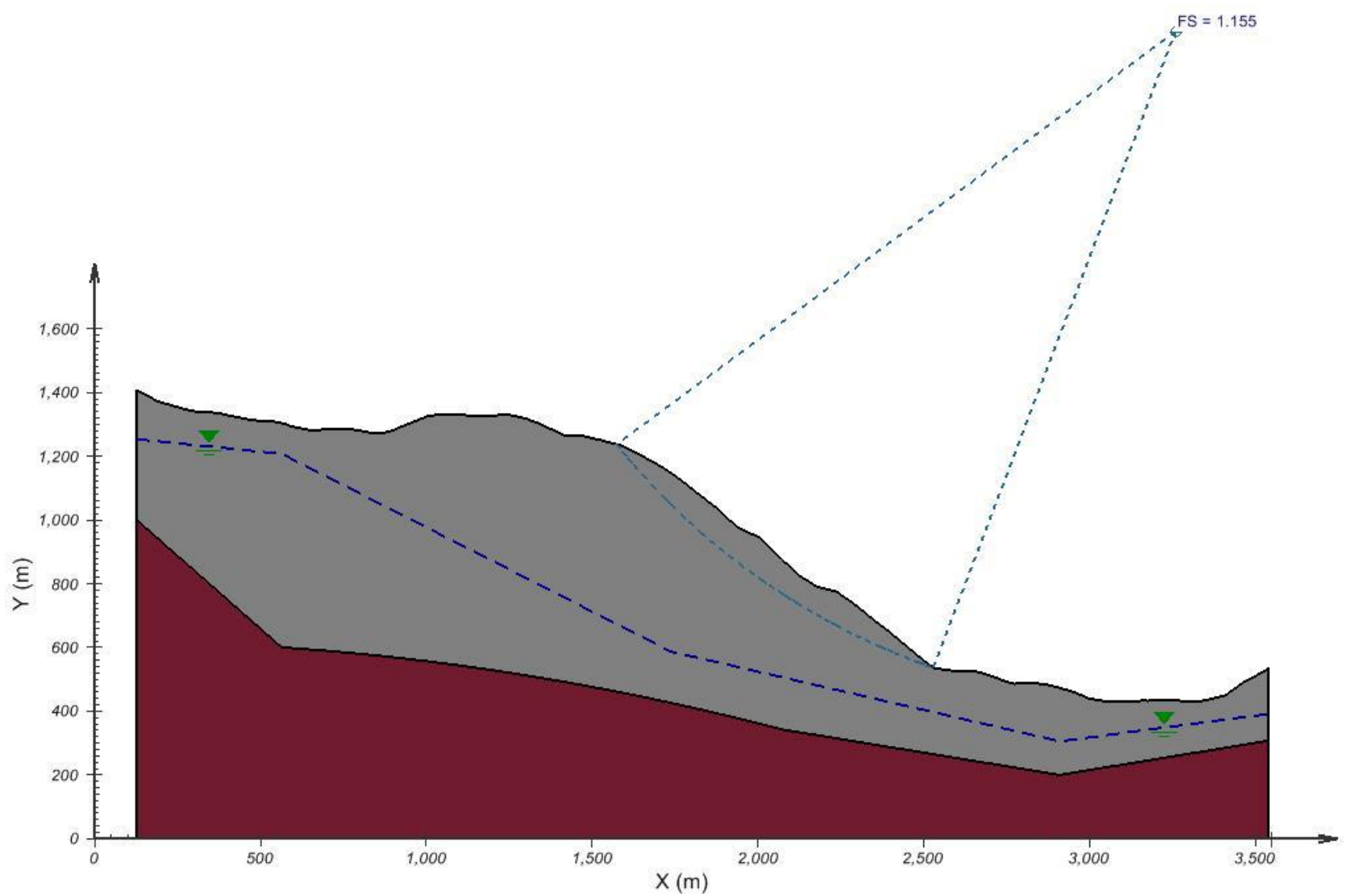

Figure 9 2D model and result based on cutting from $3 \mathrm{D}$ critical sliding direction 


\subsection{Case 3: slope direction A-A' with discontinuity and tension crack (east wall)}

For the third case, the slope direction A-A' as shown in Figure 4 is considered again with the addition of discontinuities and tension cracks. The discontinuous material parameters are cohesion equal to $1 \mathrm{kPa}$, an angle of internal friction of $25^{\circ}$, and a unit weight of $25 \mathrm{kN} / \mathrm{m}^{3}$. The discontinuity has a dip angle of $35^{\circ}$ and a dip direction parallel to the $y$-direction. In $3 \mathrm{D}$, the discontinuity is simulated using a wedge. At $x$ equal to $3,960 \mathrm{~m}$, there is a tension crack and the tension crack is filled with water. A 3D slope stability analysis without axes rotation was first performed. Figure 10 and Figure 11 show the 3D critical slip surface from different angles of viewing. Figure 11 clearly shows the discontinuity surface and tension crack surface. A 2D model cut from slope direction A-A' is created. Figure 12 shows 2D LEM critical sliding surface. The discontinuity is represented as a thin weak layer as shown in Figure 12. The FS result based on Bishop simplified method is shown in Table 3. For this slope direction and geometry layout with consideration of discontinuity and tension crack, the 3D FS is about 20\% higher than 2D FS.

Table 3 Results of ${ }_{3} D$ and $2 D$ LEM analysis based on Bishop simplified method for case 3

\begin{tabular}{cc}
\hline 3D (FS) & 2D (FS) \\
\hline 1.392 & 1.117 \\
\hline
\end{tabular}

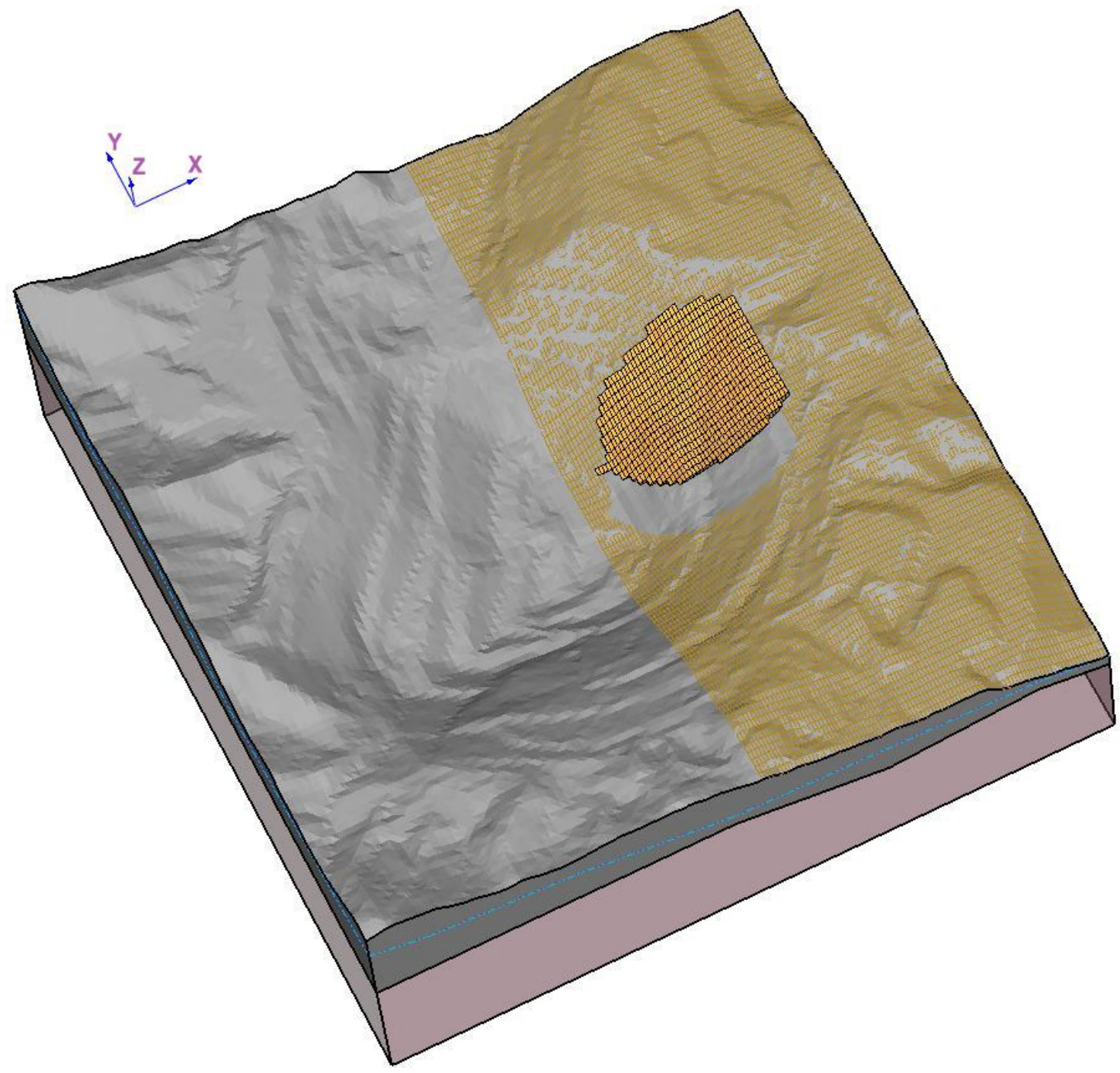

Figure $103^{D}$ critical slip surface of east wall slope direction A-A' for case 3 


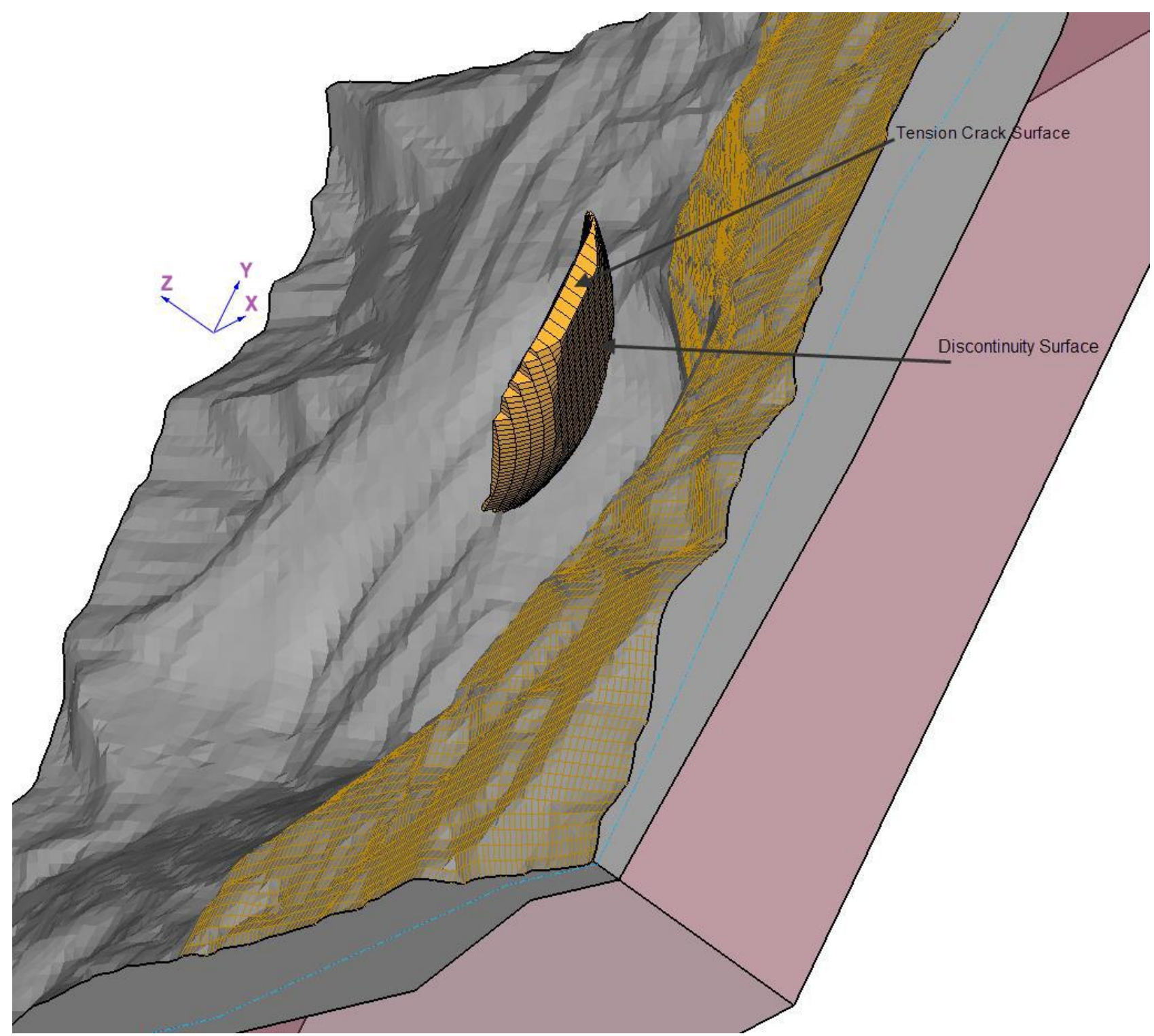

Figure 11 Another view of ${ }_{3} D$ critical slip surface of slope direction A-A' for case 3 


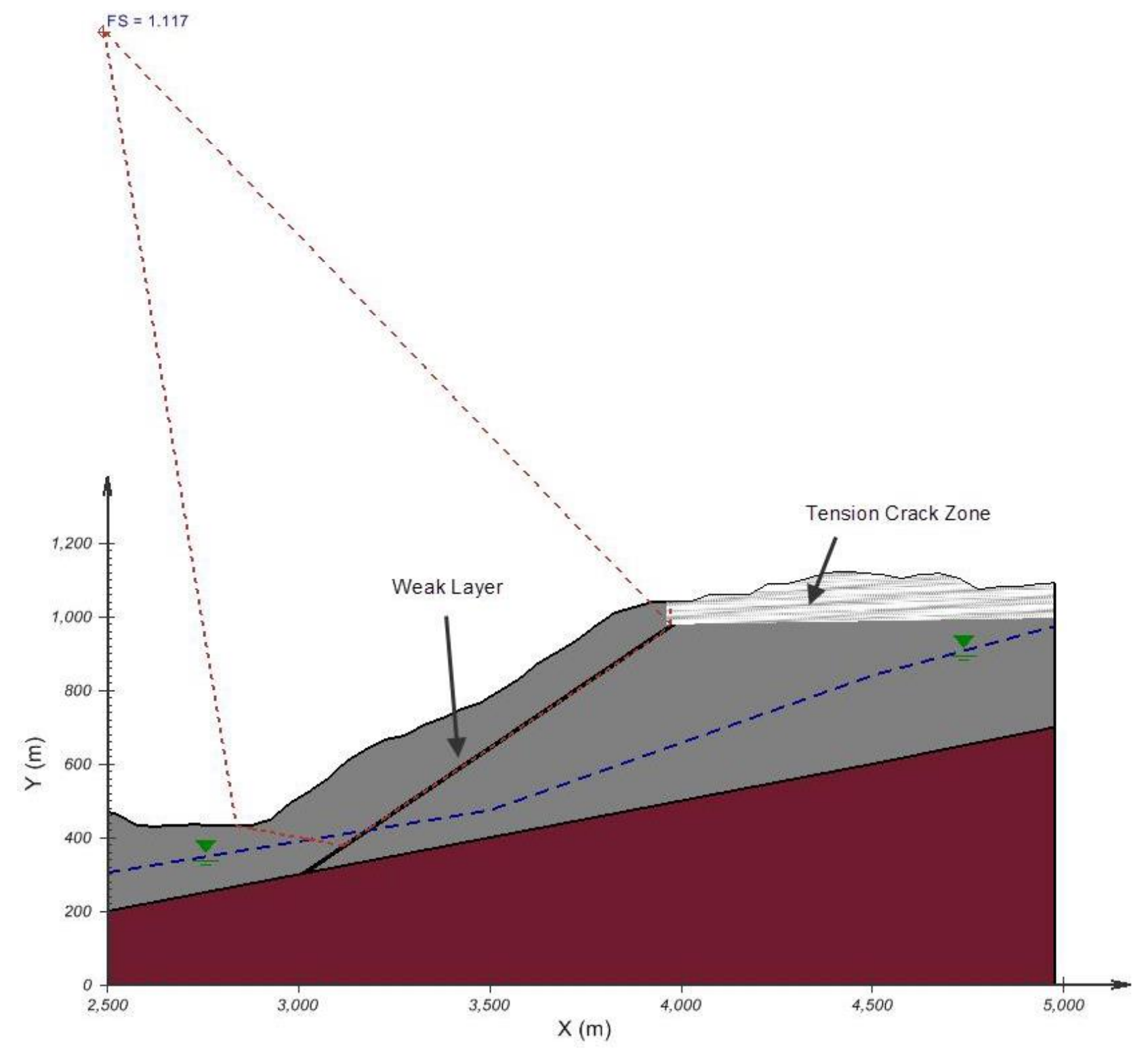

Figure 12 2D model and result based on cutting from east wall slope direction A-A'

\section{$4 \quad$ Conclusions}

Based on the case studies, it can be concluded that:

A 3D LEM analysis FS is higher than a 2D LEM analysis FS. A 2D model represents plane strain conditions without consideration of $3 \mathrm{D}$ effects. The $2 \mathrm{D}$ model in Figure 12 , for example, is actually simulating the $3 \mathrm{D}$ model as shown in Figure 13. The 3D FS calculated by SVSLOPE 3D as shown in Figure 13 is the same as the 2D FS shown in Figure 12.

To simulate an open pit mining site, a 2D FS may be too conservative. Open pit mining sites are generally highly complex since they usually contain joints, bedding planes and faults. As shown in case 3 with discontinuities, the 3D FS is about 20\% higher than the 2D FS. This case shows the largest difference between a 3D FS and a 2D FS for the above three cases analysed. The reason for the difference is the fact that the 2D model is actually simulating the 3D model shown in Figure 13 without considering the 3D effects. The weak layer is also present over its whole sliding surface. There is a big difference in shape between the 3D sliding surfaces as can be seen from Figures 11 and 13. However for the 2D model analysis, the same FS is obtained for these different 3D models. 
The 3D LEM can consider sliding at any vector angle. In other words, it is possible to search the whole 3D model and find the critical slip surface and sliding direction. This feature is extremely useful when modelling open pit 3D slope stability.

The 3D LEM allows analysis to be carried out in a practical time-frame which is consistent with current consulting practices. The model setup time is reasonable and the computation times for analysing 3D models are acceptable.

The LEM searching methods allow both local and global potential failure surfaces to be identified and the FS determined.

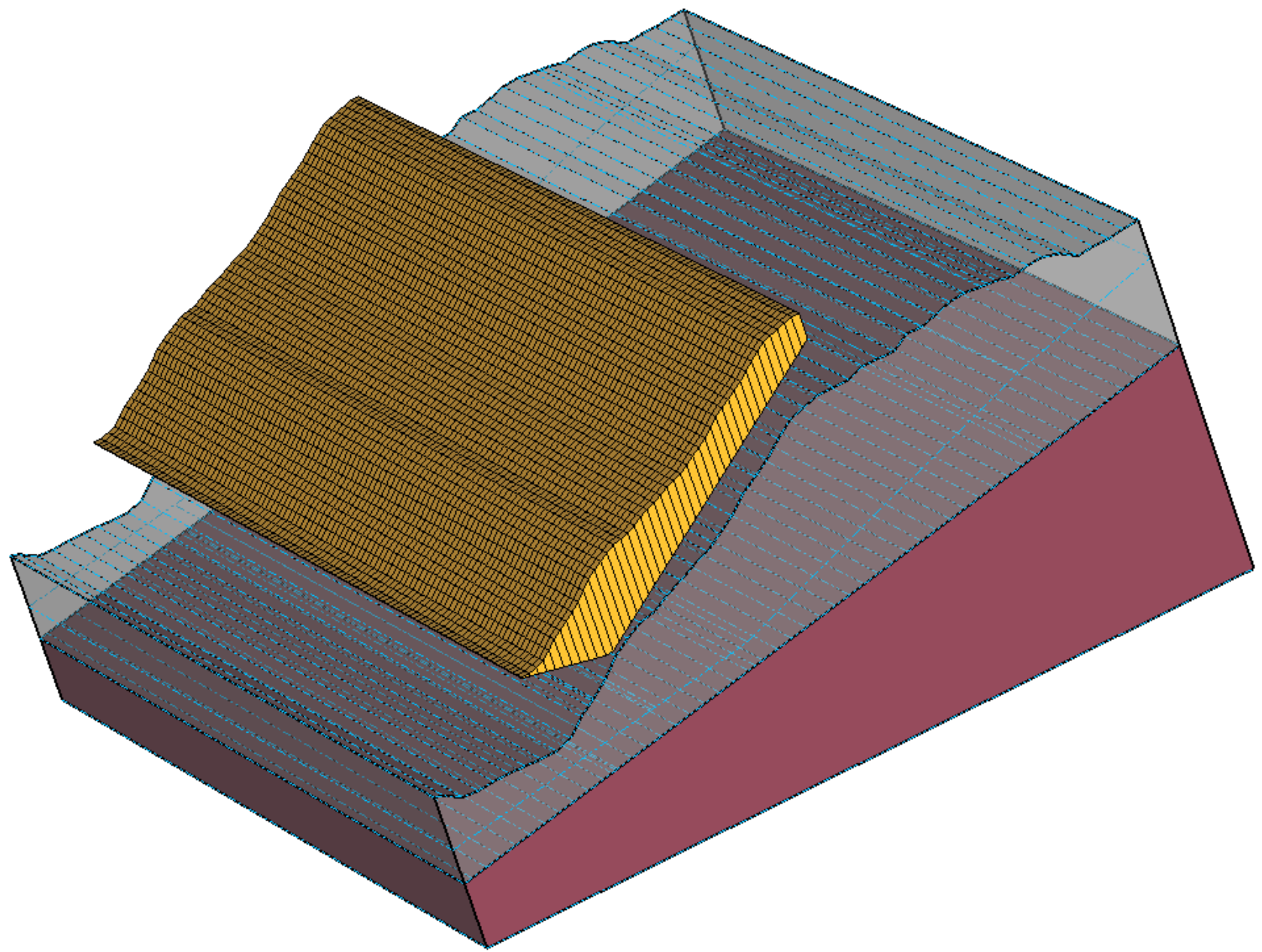

Figure 13 The actual $3 \mathrm{D}$ model that the $2 \mathrm{D}$ model in Figure 12 is simulating

\section{References}

Baker, R. (1980) Determination of the Critical Slip Surface in Slope Stability Computations, International Journal for Numerical and Analytical Methods in Geomechanics, John Wiley and Sons, Vol. 4(4), pp. 333-359.

Cavounidis, S. (1987) On the Ratio of Factors of Safety in Slope Stability Analyses, Geotechnique, Thomas Telford, Vol. 37(2), pp. 207-210.

Cheng, Y. and Yip, C. (2007) Three-Dimensional Asymmetrical Slope Stability Analysis Extension of Bishop's, Janbu's, and Morgenstern-Price's Techniques, Journal of Geotechnical and Geoenvironmental Engineering, American Society of Civil Engineers, Vol. 133(12), pp. 1544-1555.

Hovland, H.J. (1977) Three-dimensional Slope Stability Analysis Method, Journal of the Geotechnical Engineering Division, American Society of Civil Engineers, Vol. 103(9), pp. 971-986.

Hungr, O., Salgado, F.M. and Byrne, P.M. (1989) Evaluation of a Three Dimensional Method of Slope Stability Analysis, Canadian Geotechnical Journal, NRC Research Press, Vol. 26 (4), pp. 679-686.

Jiang, J.C. (1997) Determination of the Three-dimensional Critical Slip Surface in Slope Stability Analysis, PhD thesis, the University of Tokushima, Tokushima, Japan. 
Kalatehjari, R. and Ali, N. (2013) A Review of Three-Dimensional Slope Stability Analyses based on Limit Equilibrium Method, The Electronic Journal of Geotechnical Engineering, Oklahoma State University, 2013(18/A), pp. 119-134.

Lam, L. and Fredlund, D.G. (1993) A General Limit Equilibrium Model for Three-dimensional Slope Stability Analysis, Canadian Geotechnical Journal, NRC Research Press, Vol. 30(6), pp. 905-919.

Read, J. and Stacey, P. (2009) Guidelines for Open Pit Slope Design, CSIRO Publishing.

Sjöberg, J. (1996) Large Scale Slope Stability in Open Pit Mining - A Review, Technical Report, Division of Rock Mechanics, Luleå University of Technology, Sweden.

Sjöberg, J. (1999) Analysis of Large Scale Rock Slopes, PhD Thesis, Luleå University of Technology, Sweden.

Yamagami, T. and Jiang, J.C. (1997) A Search for the Critical Slip Surface in Three-dimensional Slope Stability analysis, Soils and Foundations, Vol. 37(3), pp. 1-16.

Zhang, X. (1988) Three-dimensional Stability Analysis of Concave Slopes in Plan View, Journal of Geotechnical and Geoenvironmental Engineering, American Society of Civil Engineers, Vol. 114(6), pp. 658-671. 